\title{
Daily precipitation records over mainland Spain and the Balearic Islands
}

\author{
C. Ramis ${ }^{1}$, V. Homar ${ }^{1}$, A. Amengual ${ }^{1}$, R. Romero ${ }^{1}$, and S. Alonso ${ }^{1,2}$ \\ ${ }^{1}$ Meteorology group, Physics Department, Universitat de les Illes Balears, 07122 Palma de Mallorca, Spain \\ ${ }^{2}$ Global Change Research Department, Institut Mediterrani d'Estudis Avançats, 07190 Esporles, Spain
}

Correspondence to: C. Ramis (cramis@uib.es)

Received: 29 November 2012 - Published in Nat. Hazards Earth Syst. Sci. Discuss.: Revised: 8 July 2013 - Accepted: 16 July 2013 - Published: 9 October 2013

\begin{abstract}
Understanding the spatial distribution of extreme precipitations is of major interest in order to improve our knowledge of the climate of a region and its relationship with society. These analyses inevitably require the use of directly observed values to account for the actual extreme amounts rather than analyzed gridded values. A study of daily rainfall extremes observed over mainland Spain and the Balearic Islands is performed by using records from 8135 rain gauge stations from the Spanish Weather Agency (AEMET). Results show that the heaviest daily precipitations have been observed mainly on the coastal Mediterranean zone from Gibraltar to the Pyrenees. In particular, a record value of $817 \mathrm{~mm}$ was recorded in the Valencia region in 1987. The current map of daily records in Spain, which updates the pioneering work of the Spanish meteorologist Font, shows similar distribution of extreme events but with notably higher amounts. Generalized extreme values distributions fit the Mediterranean and Atlantic rain gauge measurements and shows the different characteristics of the extreme daily precipitations in both regions. We identify the most extreme events (above $500 \mathrm{~mm}$ per day) and provide a brief description of a typical meteorological situation in which these damaging events occur. An analysis of the low-level circulation patterns producing such extremes - by means of simple indices such as NAO, WeMOi and IBEI - confirms the relevance of local flows in the generation of either Mediterranean or Atlantic episodes. WeMOi, and even more IBEI, are good discriminants of the region affected by the record precipitation event.
\end{abstract}

\section{Introduction}

Heavy rainfall is the most frequent cause of flooding, far beyond tropical cyclones, monsoonal rain or tidal surges all together (Adhikari et al., 2010). Being one of the most hazardous and damaging natural phenomena worldwide, heavy rains cause tremendous losses in terms of human life and property. The social impact from heavy rain - and associated floods - is regularly suffered across Europe, but Mediterranean countries, and primarily those in the western Mediterranean, have to cope with particularly devastating episodes. Spain, with its singular geographic and topographic features (Fig. 1), is not an exception. From 1953 to 2011, 26 exceptional floods have been registered in Spain, with an estimated damage of 8100 million inflation-adjusted USD, 1287 people killed and about 750000 affected (EM-DAT; http://www. emdat.be). As an example of especially damaging events, it can be mentioned the Biescas (northeastern Spain) flood occurred on 7 August 1996. In such a case, $225 \mathrm{~mm}$ fell in $3 \mathrm{~h}$ (between 15:00 and 18:00 UTC). In addition to the damage on many infrastructures, utilities and private properties, the flood produced 86 fatalities and 96 peoples became injured (Romero et al., 2001). Similarly, in the southern part of France, on 8 and 9 September 2002, a heavy precipitation event was responsible of the most important flooding ever recorded in the Cevennes-Vivarais region. The event resulted in 24 people killed, and the economic damage was estimated at 1.2 billion euros (Anquetin et al., 2005).

An interesting climatic product for a region is the spatial distribution of daily precipitation extremes. A study of daily rainfall extremes observed over the Iberian Peninsula (Spain and Portugal) was carried out by Font (1983) using data from 


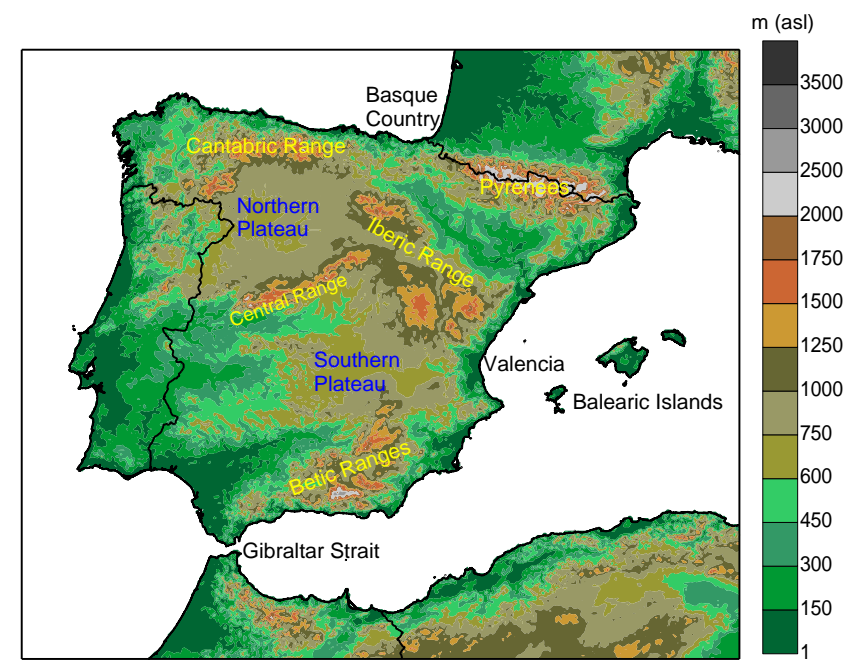

Fig. 1. Orography of the Iberian Peninsula. Locations referred to in the text are indicated.

1931 to 1960 (Fig. 2). Font's map shows that the heaviest daily precipitations were observed mainly on the Mediterranean coastal lands, from Gibraltar to the Pyrenees, with many reports exceeding $200 \mathrm{~mm}$. Special emphasis was put on the Valencia region, where a small area with values exceeding $400 \mathrm{~mm}$ emerged in his results. Font's pioneering work also showed that more than $200 \mathrm{~mm}$ had been recorded in parts of the Cantabrian coast (especially the Basque Country) and in locations on one of the major mountain systems of the Iberian Peninsula (Central Range). On the other hand, Font (1983) revealed that most points of the Northern and Southern Plateaus have never recorded daily precipitations in excess of $100 \mathrm{~mm}$ up to 1960 .

Since 1960, many more rain gauge stations have been added to the AEMET network, but also torrential amounts of daily rainfall have been recorded in mainland Spain, substantially higher than those shown in the Font's classical book. It seems convenient, then, to revise those results with the currently available records. Therefore, the aim of this paper is to commemorate the work of Font (1983) and update his classical map of the spatial distribution of maximum observed daily precipitation over mainland Spain using current databases and methodological standards. Unlike in the original publication, we consider in this study the Balearic Islands, which hold the densest network of precipitation observation stations in Spain. We characterize the seasonal spatial disposition of daily rainfall records as well as their frequency distribution, which is fitted remarkably well with generalized extreme values (GEV) distributions, either when using all stations in the dataset or when Mediterranean (MED) and Atlantic (ATL) sites are grouped. In addition, we investigate the relationship between record days and some largescale circulation indexes such as the North Atlantic Oscillation (NAO; Hurrell, 1995) and more local indexes such

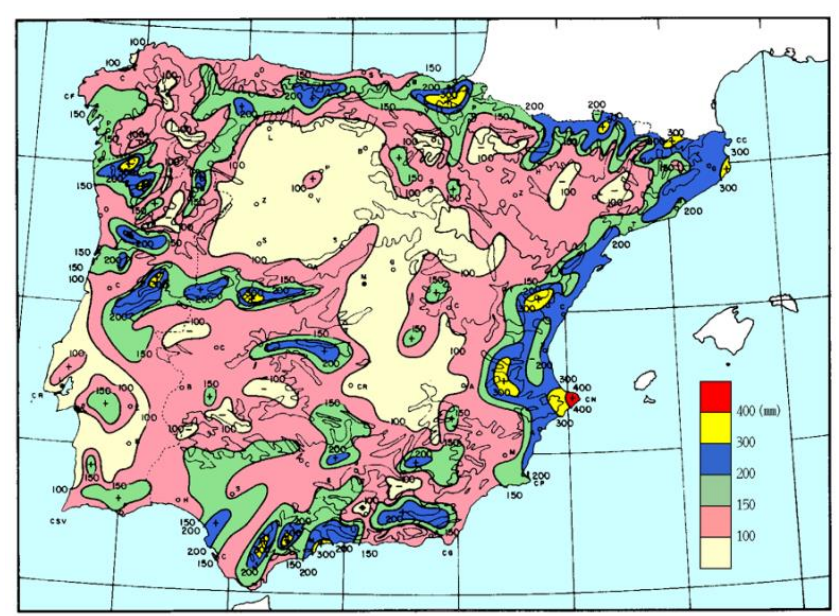

Fig. 2. Daily precipitation records for the Iberian peninsula from 1931 to 1960 . Colors indicate precipitation according to the scale (from Font, 1983).

as the western Mediterranean Oscillation (WeMOi; MartínVide and Lopez-Bustín, 2006) and our proposed Iberian index (IBEI). Finally, for the sake of the context in which these episodes develop, we also briefly discuss the meteorological situation that produced the most extreme daily precipitation amount ever recorded in Spain.

\section{Daily rainfall records}

The AEMET operate and maintains a data base of daily (07:00 to 07:00 UTC) precipitation amounts that covers the entire Spanish territory. Before 1910, the number of stations is marginal but during the next decades it grew until about 2000 station in 1950. The network reached its maximum size during the seventies and eighties, with nearly 5000 active rain gauge sites. Altogether, we have used 8135 rain gauge stations, with data starting from the date each one was installed until 31 December 2008. However, our data base in each AEMET rain gauge station does not contain temporal information except for the date the record was registered. We performed a basic quality control on the data for each station to filter out transcription errors, such as evident unrealistically low and high records. In order to analyze actual record values, we use direct observed values rather than interpolated fields, as these inevitably omit extreme amounts due to the smoothing introduced by the analysis method used to generate them.

The spatial distribution of the updated highest daily rainfall value ever recorded at each station of the network (Fig. 3) in mainland Spain is quite similar to the one shown by Font (1983), but the amounts have changed significantly. In fact, the most intense precipitations tend to occur along the Mediterranean coastal areas, from the Gibraltar strait to 


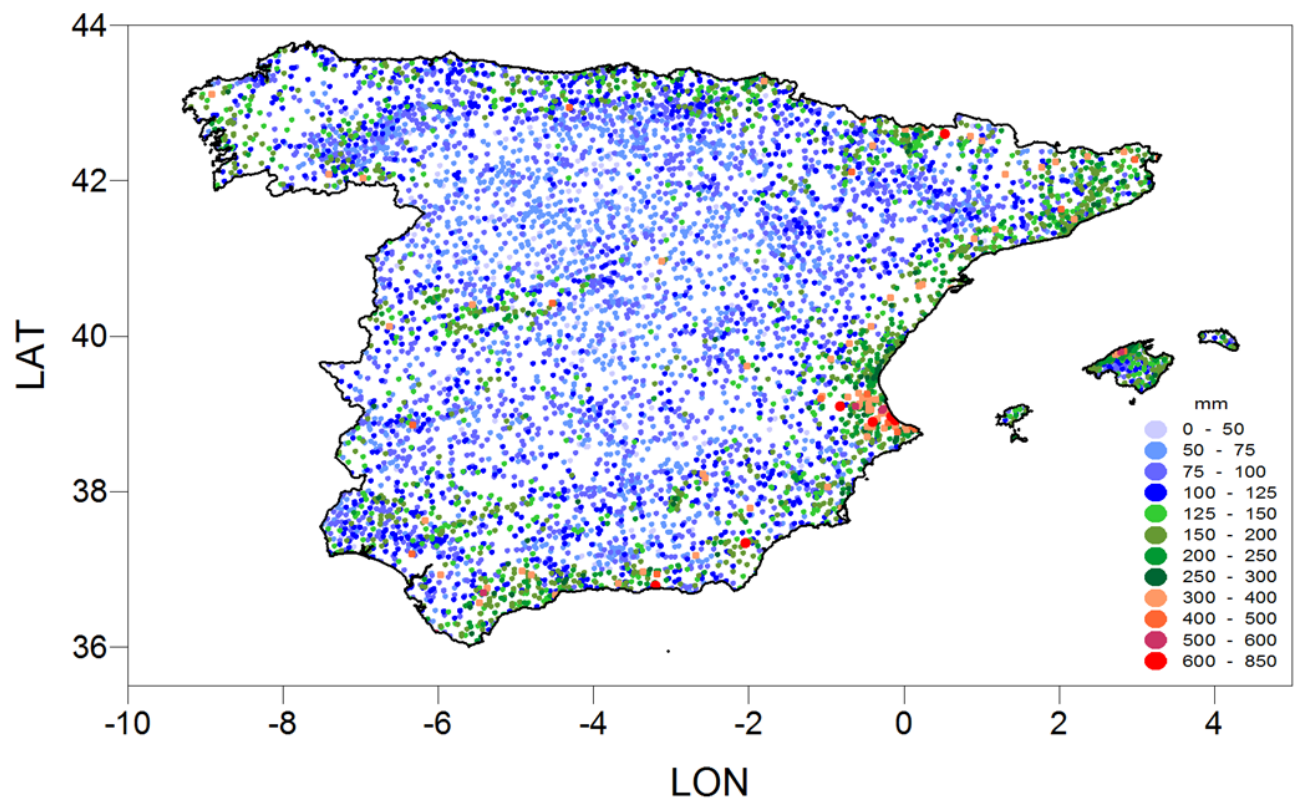

Fig. 3. Daily precipitation records for mainland Spain and Balearic Islands. Points show the locations of the rain gauge stations and colors indicate extreme precipitation amounts according to the scale.

the Pyrenees, where most of the rain gauge stations have recorded daily precipitations above $125 \mathrm{~mm}$. More than a few stations, also along the Mediterranean coast, have recorded quantities greater than $300 \mathrm{~mm}$. It is interesting to note that the most copious precipitations are very concentrated in the Valencia region, where several gauge stations have registered more than $600 \mathrm{~mm}$ and one observation exceeds $800 \mathrm{~mm}$. Locations of the northern coastal region and interior mountain ranges, especially in the Central Range, have many stations with records above $200 \mathrm{~mm}$, although $300 \mathrm{~mm}$ have also been registered in isolated stations. The locations with lower maximum registered values (below $100 \mathrm{~mm}$ ) are mainly found in the Northern Plateau. Regarding the Balearic Islands, many rain gauge stations have recorded daily precipitations in excess of $250 \mathrm{~mm}$. However the highest rainfalls ever recorded occurred in the mountainous northern area of the island of Mallorca, close to the highest peaks of the range, with amounts reaching $400 \mathrm{~mm}$ and one observation of $536.5 \mathrm{~mm}$. Overall, $54 \%$ of the stations in the data base never registered maximum daily amounts above $100 \mathrm{~mm}$ and only $1.3 \%$ (i.e. 105 stations) have measured amounts exceeding $300 \mathrm{~mm}$ (see Table 1). Most of these 105 extreme values arise on the eastern coastlands of the Iberian Peninsula and eastern Pyrenees, especially concentrated in the Valencia region (Fig. 4).

Interestingly enough, 7 of the 13 stations with maximum daily precipitation amounts exceeding $500 \mathrm{~mm}$ are located in the Valencia region (see Table 2). Despite orography, there is a well-documented mechanism for convection initiation - through direct uplift - and heavy rainfall anchoring in Mediterranean Spain (e.g. Romero et al., 1997); some of the most extreme records $(817 \mathrm{~mm}$ and $720 \mathrm{~mm}$ ) are found on
Table 1. Distribution of the number of rain gauge stations per interval of maximum daily precipitation $(\mathrm{mm})$.

\begin{tabular}{llll}
\hline$P<100$ & $100<=P<200$ & $200<=P<300$ & $300<=P$ \\
\hline 4365 & 3175 & 490 & 105 \\
\hline
\end{tabular}

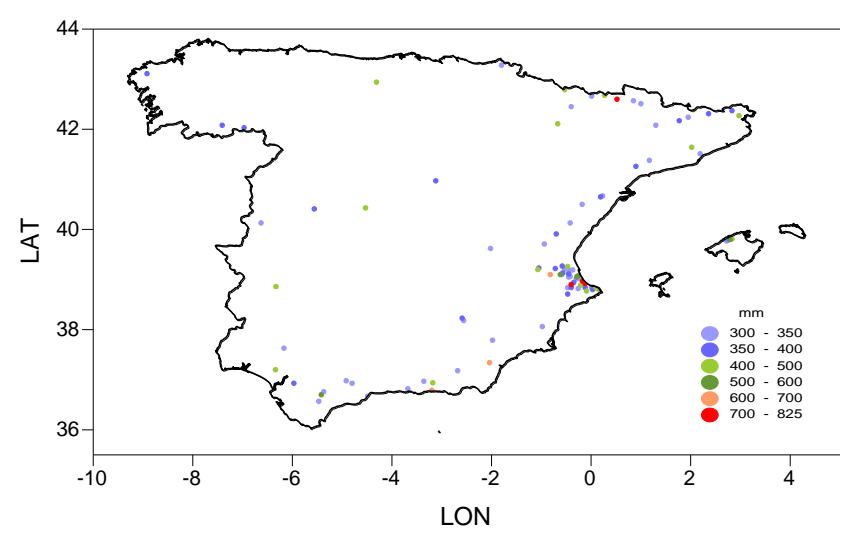

Fig. 4. Location of rain gauges with maximum registered daily precipitations greater than $300 \mathrm{~mm}$. Colors indicate precipitation amounts according to the scale.

the coastline, hardly above sea level. It is also interesting to note that 4 out of 13 cases listed in Table 2 correspond to the same heavy rain event (3-4 November 1987), in which 5 rain gauges recorded values in excess of $400 \mathrm{~mm}$ and 18 exceeded the $300 \mathrm{~mm}$ threshold. 
Table 2. Spanish daily rainfall records exceeding $500 \mathrm{~mm}$ in the database (until 2008).

\begin{tabular}{lrrrr}
\hline Province & $\begin{array}{r}\text { Rain } \\
\text { gauge } \\
\text { identifier }\end{array}$ & $\begin{array}{r}\text { Altitude } \\
(\mathrm{m} \text { a.s.1.) }\end{array}$ & $\begin{array}{r}\text { Precipitation } \\
(\mathrm{mm})\end{array}$ & Date \\
\hline Valencia & $8058 \mathrm{~A}$ & 20 & 817.0 & 3 Nov 1987 \\
Valencia & $8288 \mathrm{E}$ & 243 & 790.0 & 4 Nov 1987 \\
Valencia & $8071 \mathrm{C}$ & 22 & 720.0 & 3 Nov 1987 \\
Huesca & $9838 \mathrm{~B}$ & 1138 & 700.5 & 22 Nov 1923 \\
Valencia & $8270 \mathrm{O}$ & 700 & 632.0 & 20 Oct 1982 \\
Granada & 6275 & 240 & 600.0 & 19 Oct 1973 \\
Almeria & 6366 & 240 & 600.0 & 19 Oct 1973 \\
Balearic & & & & \\
Islands & $\mathrm{B} 684$ & 830 & 536.5 & 22 Oct 1959 \\
Cádiz & 5944 & 793 & 525.0 & 13 Dec 1987 \\
Valencia & $8274 \mathrm{U}$ & 40 & 520.0 & 4 Nov 1987 \\
Valencia & 8077 & 17 & 520.0 & 11 Sep 1996 \\
Cádiz & 5979 & 22 & 503.0 & 27 Jan 1960 \\
Valencia & 8076 & 35 & 500.0 & 11 Sep 1996 \\
\hline
\end{tabular}

The systems that produce these coastal extreme rainfalls are most frequently organized mesoscale convective systems (MCS) that often do not reach the size and structure of a mesoscale convective complex (MCC, Maddox, 1980). These MCS are usually stationary, bearing persistent and copious rainfall on the affected locations. Autumn is the most favorable time of the year for the development of MCS in the western Mediterranean (Riosalido et al., 1988).

The spatial distribution of seasonal daily record precipitation shows the greatest number of extremes during fall, mostly concentrated along the Mediterranean coastlands (Fig. 5). The highest daily record precipitation events are also more frequent in autumn and located mainly on the Mediterranean coastal areas, near the Pyrenees and along the highest mountain ranges. Most stations in the Balearic Islands registered their current record value in the fall. On the other hand, the highest density of stations with records during the wintertime sites in the western half of the peninsula, focusing on the mountainous areas of northern, central and southern Spain. Likewise, the winter records of the Balearics are found only in the mountainous areas of the island of Mallorca. The spring shows the lowest number of extreme events with a fairly regular spatial distribution across the study area (Fig. 5); although a slightly higher concentration becomes visible in the Basque Country. Interestingly, spring records exceeding $300 \mathrm{~mm}$ are found on the Mediterranean coast and the Pyrenees. In summer most precipitation records concentrate in the northeast of the Iberian Peninsula, as during this time of the year the eastern part of the Iberian range becomes a well-known and efficient storm nest. The humid air from the Mediterranean favors the development of convective clouds that, in many cases, result in hail or heavy precipitation in the northeastern Iberian Peninsula (e.g. Sánchez et al., 2003). During this season the number of registered records in the southern half of Spain is very low.
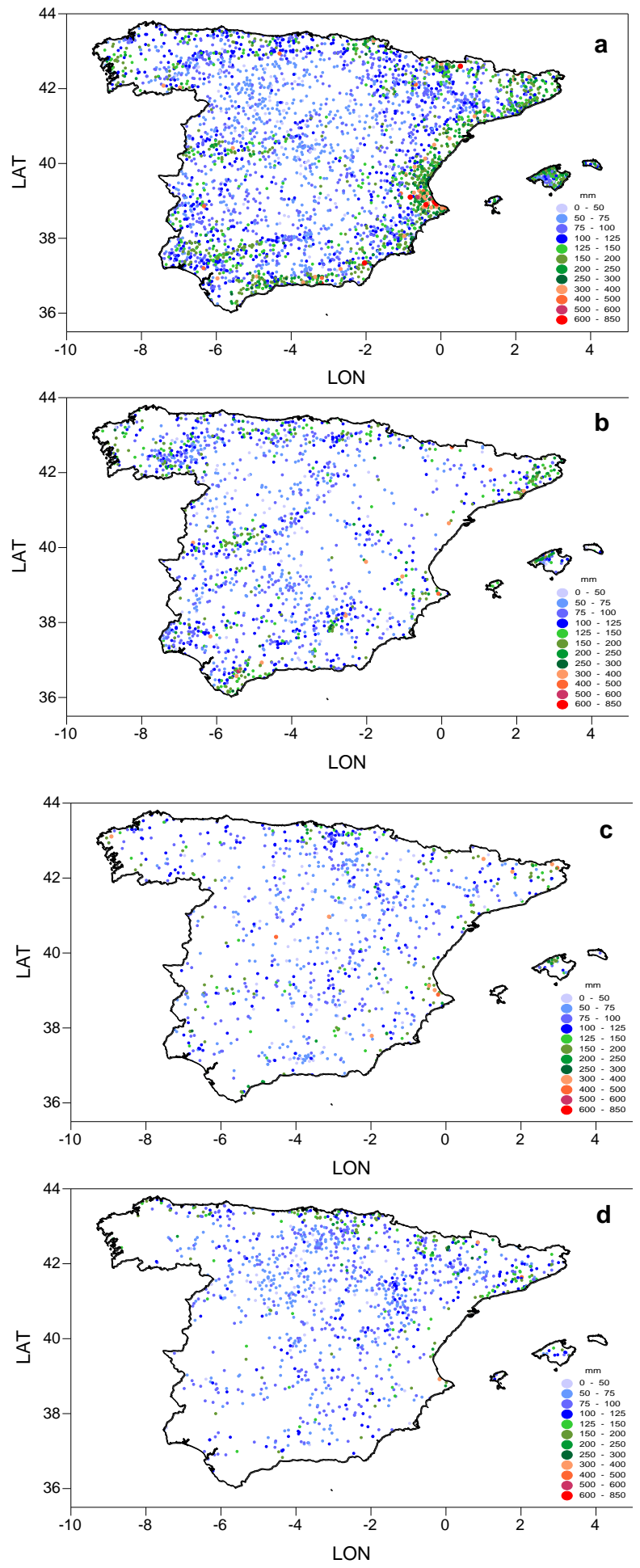

Fig. 5. Seasonal spatial distribution of extreme daily rainfall. (a) autumn (4185 data); (b) winter (1694 data); (c) spring (977 data); (d) summer (1279 data). 
Table 3. Parameters of the three GEV distributions shown in Fig. 7 b.

\begin{tabular}{lrrr}
\hline \multirow{2}{*}{ Region } & \multicolumn{3}{c}{ GEV parameters Median $(95 \%$ confidence interval) } \\
\cline { 2 - 4 } & Shape & Location $(\mathrm{mm})$ & Scale \\
\hline All stations & $0.22(0.20,0.24)$ & $83.97(83.18,84.80)$ & $32.32(31.68,32.99)$ \\
Mediterranean & $0.16(0.13,0.18)$ & $102.70(100.96,104.34)$ & $42.71(41.44,43.95)$ \\
Atlantic & $0.15(0.12,0.17)$ & $75.80(75.01,76.63)$ & $25.25(24.64,25.79)$ \\
\hline
\end{tabular}

The different characteristics of the stations with Mediterranean influence with respect to the more Atlantic zones are clearly appreciable in Figs. 3, 4 and 5. Indeed, a more systematic investigation of these differences can be done by analyzing the distribution of maximum registered precipitation values in the Mediterranean regions and comparing it to the rest of the study area. Taking a pragmatic definition of Mediterranean rain gauges such as those in the database located in the autonomic communities close to the Mediterranean (Fig. 6; Romero et al., 1998), the sample of 8135 is thus classified into 3333 Mediterranean (MED) and 4802 Atlantic (ATL) sites. Figure 7a shows the empirical distribution of maximum precipitations for the entire database along with a generalized extreme value (GEV, Jenkinson, 1955) distribution fit. The shape, location and scale parameters for the fitted distribution are obtained as the median of a bootstrapgenerated population of maximum likelihood estimates (Venables and Ripley, 2002) applied to samples of the same length as the original, but allowing repetition. The bootstrap procedure, applied to over 1000 resamples, not only allows for a more robust estimate of the GEV distribution parameters but also provides their confidence intervals (Table 3 ). In addition to the qualitative assessment of the goodness of the fit achievable on Fig. 7a, the relatively narrow confidence intervals for the GEV parameters add upon the capacity certainty of the fitted function to capture the main characteristics of the underlying extreme precipitation data.

By using the same method, two additional GEV distributions are fitted to the MED and ATL extreme values, correspondingly (Fig. 7b). The comparison of these distributions clearly reveals significant differences among the underlying populations. The Mediterranean stations show larger extreme values, as confirmed by the mode (e.g. location parameter of $102.70 \mathrm{~mm}$ compared to the $75.80 \mathrm{~mm}$ for the ATL) and the higher density near the $200 \mathrm{~mm}$ range (e.g. heavier right tail in the MED distribution). Making use of the fitted distributions, the probability of a station in a given region having a record precipitation measure above certain threshold is trivially computed. For instance, the probabilities of finding a station with the record value exceeding the 100, 200 and $300 \mathrm{~mm}$ levels are $(0.66,0.13,0.03)$ for the MED and $(0.33$, $0.02,<0.01)$ for the ATL.

A characterization of extreme precipitation days in relation to the low level atmospheric circulation is made based on the cumulative distribution function (CDF) of some

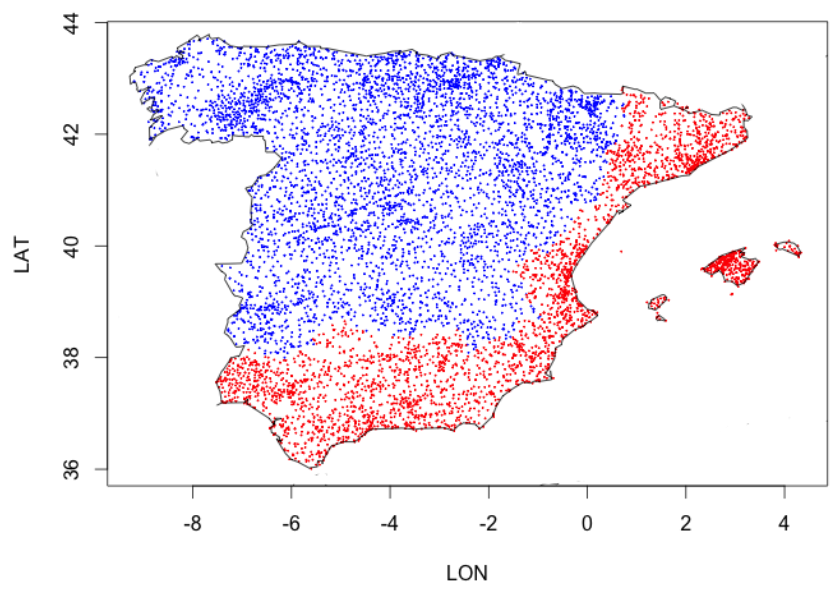

Fig. 6. Mediterranean (MED, red) and Atlantic (ATL, blue) rain gauge stations.

atmospheric circulation indexes corresponding to the record precipitation days, separately analyzing Mediterranean and Atlantic stations, and comparing with the corresponding climatological CDF. We considered the NAO index, the WeMOi and finally defined a new index, IBEI, which focuses on the dominant flow pattern over the Iberian Peninsula. A similar study was conducted by Valencia et al. (2012) for the Ebro River basin using NAO and WeMOi indexes. Daily NAO values from 1951 were obtained from the NCEP/Climate Prediction Center. The WeMOi index was defined as the pressure difference at sea level, and standardized between San Fernando (Spain) and Padua (Italy) by Martín-Vide and Lopez-Bustín (2006). For daily values, this difference has been replaced by the pressure difference, and normalized between points $\left(5^{\circ} \mathrm{W}, 35^{\circ} \mathrm{N}\right)$ and $\left(10^{\circ} \mathrm{E}, 45^{\circ} \mathrm{N}\right)$ of the ECMWF/ERA-40 analysis. A new index (IBEI), even more local, has been defined as the pressure difference, normalized, between points $\left(5^{\circ} \mathrm{W}, 35^{\circ} \mathrm{N}\right.$; near Gibraltar) and $\left(2.5^{\circ} \mathrm{W}, 45^{\circ} \mathrm{N}\right.$; near the Gulf of Biscay). Positive (negative) values of this proposed index represent westerly (easterly) flows over the Iberian Peninsula.

The CDFs for these indexes (Fig. 8) reveal a few interesting features linked to the most favorable flows for the generation of extreme precipitation episodes in the region. The NAO index is not a good discriminant for Mediterranean and Atlantic events, as a consequence of NAO being an index of large-scale circulation over the Atlantic. As such, it is not 


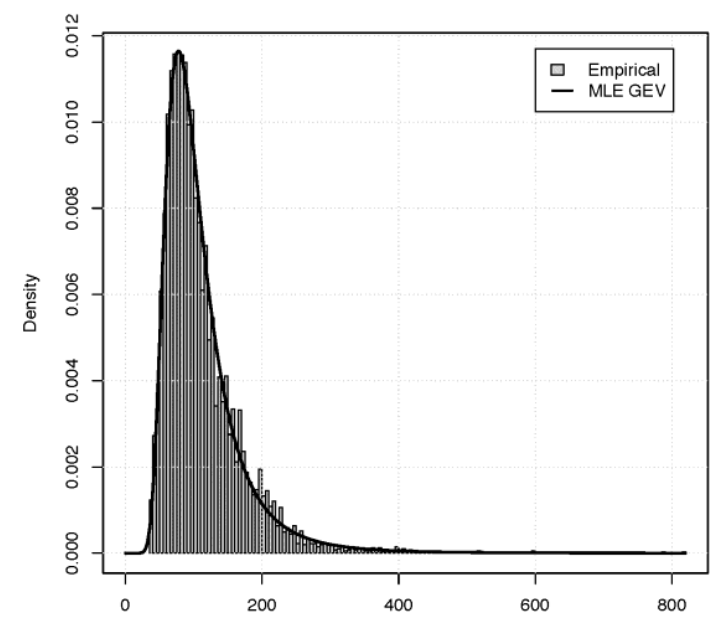

(a)

Max daily PCP (mm)

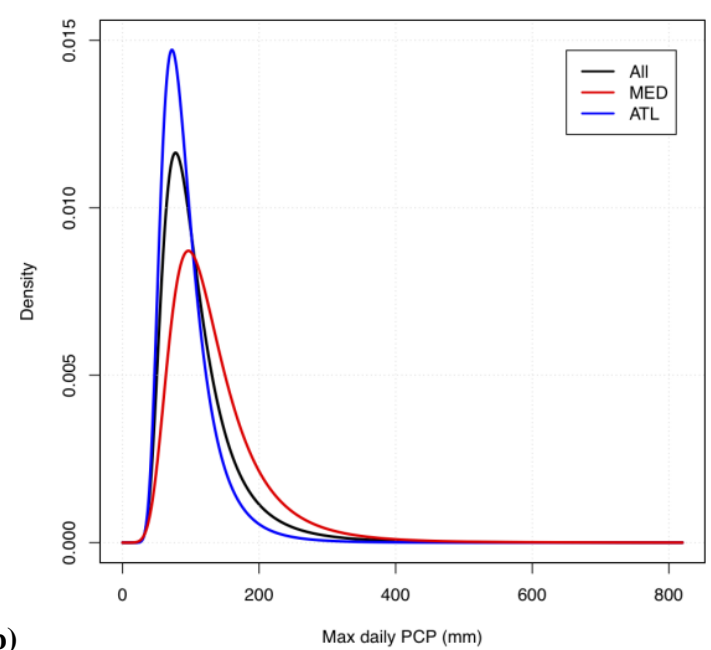

Fig. 7. (a) Empirical histogram of record daily precipitation values for all the rain gauges in the database and the corresponding fitted GEV distribution. Fitted parameters are provided (median) in Table 3. (b) Comparison of GEV distributions fitted to all stations in the database (ALL), Mediterranean sites (MED) and Atlantic stations (ATL).
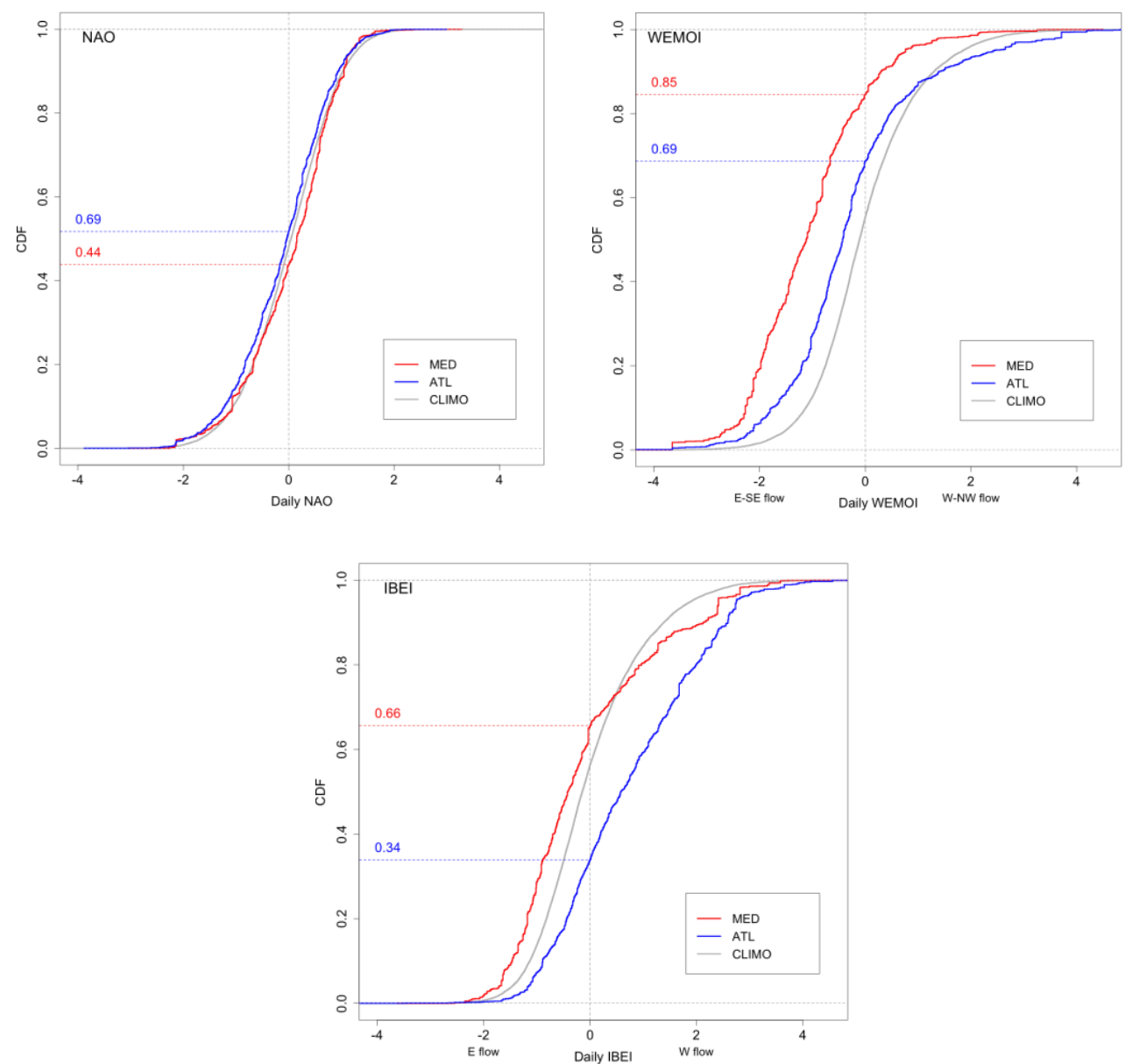

Fig. 8. Cumulative distribution functions of daily values corresponding to NAO, WeMOi and IBEI. Gray lines correspond to values from 1 January 1950 to 31 March 2013 for NAO and from 1 September 1957 to 31 August 2002 for WeMOi and IBEI. Red and blue lines correspond to the values of daily NAO, WeMOi and IBEI for MED and ATL extreme precipitation days, respectively. 

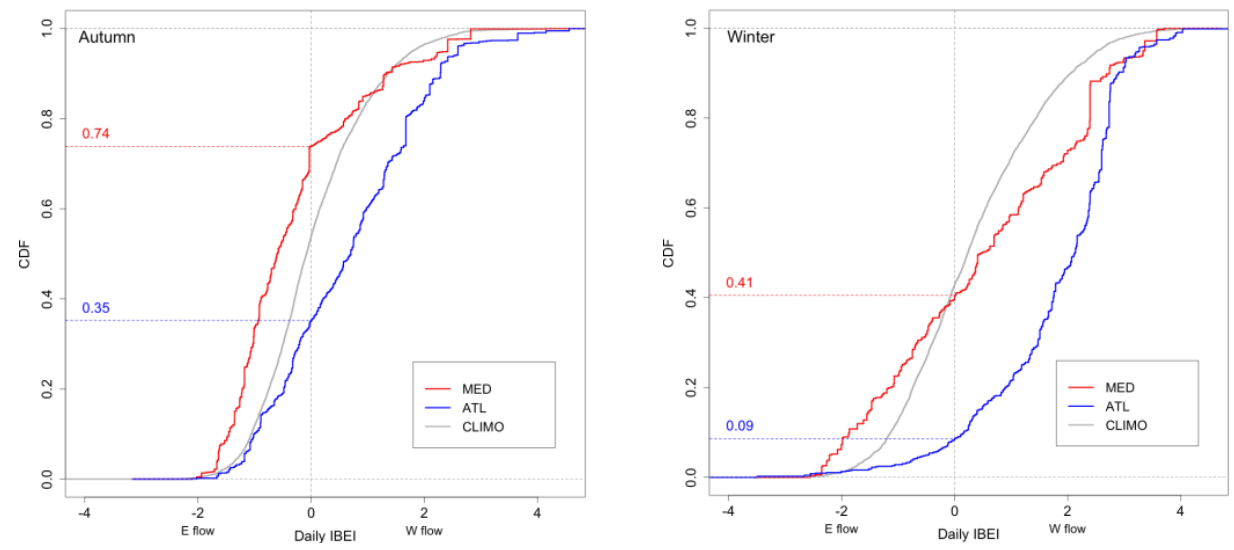

Fig. 9. Seasonal cumulative distribution function for daily values of IBEI. Line colors as in Fig. 8.

representative of smaller-scale circulations determining the peculiar details that affect the processes involved in the majority of situations of heavy rain in the Iberian Peninsula. Both WeMOi and IBEI turn out to be much better discriminants. The WeMOi results show that $85 \%$ of Mediterranean extreme rainfall cases occur under E-SE flow, although $69 \%$ of Atlantic cases are also registered with the same flow. IBEI emerges as the best discriminant, indicating that $66 \%$ of Mediterranean extreme cases occur under easterly flows whereas $66 \%$ of Atlantic records occur with westerly flow.

Figure 5 reveals that the largest number of recorded daily precipitation events, as well as the most intense, occurs in autumn and winter. We analyzed the seasonal CDF of recorded rainy days for the IBEI index and Fig. 9 shows the results for autumn and winter. Remarkably, IBEI shows great discrimination between Mediterranean and Atlantic autumn cases. Indeed, $74 \%$ of Mediterranean and only $35 \%$ of Atlantic autumn records are registered under easterly dominant flow. Conversely, winter IBEI also shows great discrimination, with $41 \%$ of Mediterranean cases occurring with easterly flow and $91 \%$ of Atlantic cases recorded under westerly flow.

These clearly differentiated statistical characteristics of the region, with Mediterranean influence as compared to the Atlantic regions of the Iberian Peninsula, are then attributable to the meteorological conditions in which these records are typically measured. The next section provides an example of such meteorological settings.

\section{Meteorological conditions of the highest extreme event}

The highest daily precipitation ever recorded in Spain corresponds to the 3 November 1987 (Table 2) with $817 \mathrm{~mm}$ in the station of Oliva (Valencia). An MCS affected the coastlands of Valencia during the early morning of 4 November 1987 (Fig. 10), producing very intense precipitation. Similarly, the precipitation that day was quite significant $(>100 \mathrm{~mm})$

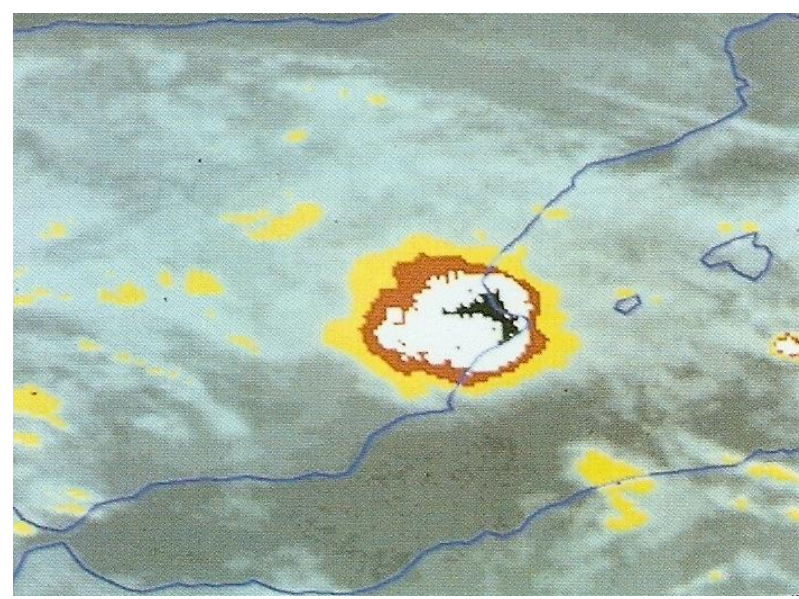

Fig. 10. Meteosat IR image on 05:30 UTC, 4 November 1987. Red, white and black pixels indicate temperatures below $-42,-54$ and $-64{ }^{\circ} \mathrm{C}$, respectively.

across Valencia but the extreme amounts were notably concentrated on the coastal lands (Fig. 11, Riosalido et al., 1988).

On 4 November 1987 at 00:00 UTC, surface low pressures over northern Africa and to the west of the Iberian Peninsula, together with a prominent blocking anticyclone over the British Isles, configured the low-level synoptic environment for that event (Fig. 12). This configuration produced easterly flow over the western Mediterranean that favored the advection towards Spain of the warm air that extends from inland North Africa into the Mediterranean (Fig. 13). As a result of this easterly warm flow, a strong temperature gradient formed with warm and humid air over the western Mediterranean sea and colder and dry air over the Iberian Peninsula, defining the thermal setting at low levels. In such a case, the easterly flow that impinges on the coastal orography released the strong latent instability and triggered deep moist convection. 


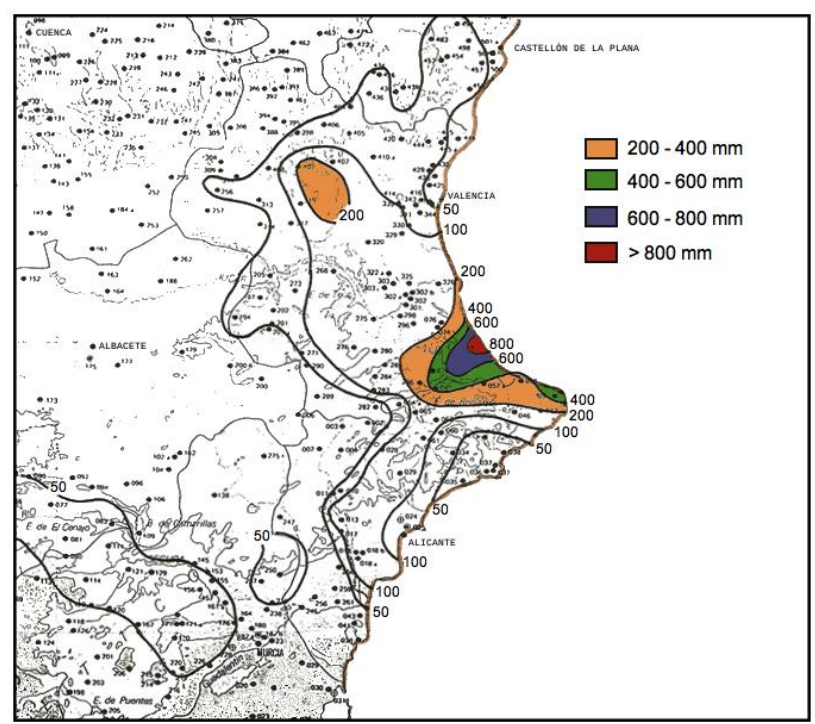

Fig. 11. Spatial distribution of rainfall for 3 November 1987. Colors highlight the areas with the most intense precipitation amounts according to the scale (from Riosalido et al., 1988).

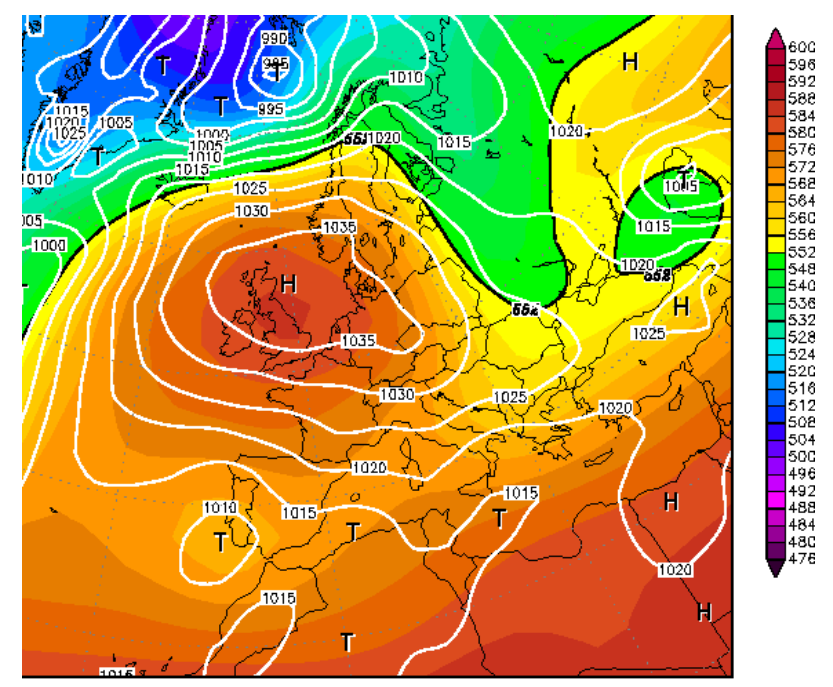

Fig. 12. NCEP reanalysis for 4 November 1987 at 00:00 UTC. White lines depict isobars $(\mathrm{hPa})$ at sea level. Colors indicate geopotential at $500 \mathrm{hPa}$ in gpdam according to the scale.

High values of precipitable water $(35 \mathrm{~mm})$ were present over the Mediterranean as it is deduced from the radiosounding launched in Mallorca on 3 November at 12:00 UTC. The $500 \mathrm{hPa}$ map shows that the dominant high over British Isles covered the entire troposphere. The cold low to the west of the Iberian Peninsula (Fig. 12) produced weak southwesterly flow over the Spanish Mediterranean coast. The low to the west of the Iberian Peninsula dynamically forced the synoptic upward vertical motions over Spain and in turn, favors the development of convection. The importance of shallow

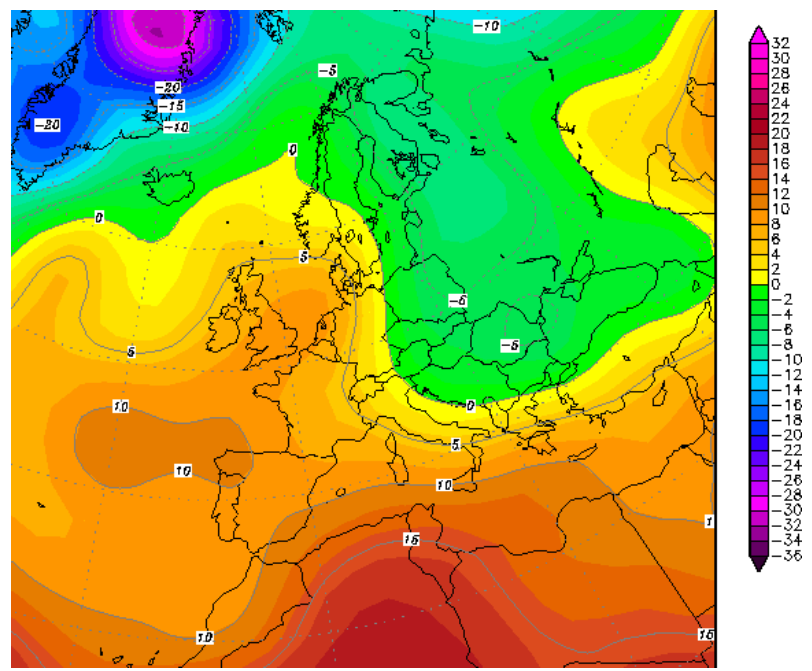

Fig. 13. NCEP reanalysis for 4 November 1987 at 00:00 UTC. Colors indicate temperature at $850 \mathrm{hPa}$ according to the scale.

mesoscale lows, which act as catalyzers of the intense precipitations by focusing the easterly flow over a specific area of the Spanish Mediterranean region, is described in Romero et al. (2000).

Romero and Ramis (1999) used statistical methods to identify links between Mediterranean Spanish torrential rainfall episodes and favorable synoptic meteorological situations, using 925 and $500 \mathrm{hPa}$ fields. They showed the prevalence of low-level flows linked to low pressure systems over northern Africa and high pressures over Europe, which produce warm and moist easterly flow from the Mediterranean towards the Spanish coast. Then, the local orographic systems act as a physical lifting mechanism. At mid tropospheric levels, a cold trough or possibly a closed cold low is usually identified to the west-southwest of the Iberian Peninsula and a ridge is located over central Europe, favoring the stationarity of the situation. Indeed, the meteorological situation of 4 November 1987 matches remarkably well the conceptual model that explains the heavy coastal rains in Mediterranean Spain.

\section{Conclusions}

This paper aims at providing an update of the classical map of Font (1983) on the record rainfalls in the Iberian Peninsula and has corroborated the spatial distribution of extreme precipitations presented in his pioneering book some $30 \mathrm{yr}$ ago. Indeed, the most extreme rainfall cases ever recorded in Spain occurred in the Mediterranean coastlands mainly in the Valencia region, whereas the plateaus (especially the northern one) have registered much more modest daily maximum precipitation amounts. This paper also shows that daily rainfall maxima extremes registered in Mediterranean Spain are 
certainly outstanding, with some of these among the highest values ever recorded worldwide. In the case of 3 November 1987 , values up to $817 \mathrm{~mm}$ in $24 \mathrm{~h}$ were registered in Valencia.

A generalized extreme value distribution fit demonstrates that this probability function adequately describes the distribution of the recorded extreme values in mainland Spain and the Balearic Islands. The statistical analysis provides a quantification of the different characteristics of the stations with Mediterranean and Atlantic influences, confirming the more hazardous character of the Mediterranean extreme precipitations. The number of stations with maximum recorded values exceeding extreme thresholds is significantly larger in the Mediterranean region than elsewhere in the study area. Local circulation indexes (WeMOi and especially IBEI) are shown to be effective discriminants of the atmospheric patterns prone to the generation of MED and ATL daily record precipitations. For autumn, $74 \%$ of the extreme rainfall days in the Mediterranean area are produced by easterly fluxes, whereas $91 \%$ of the Atlantic cases are produced under westerly winds during the winter season.

The meteorological situations that produce heavy rain in eastern Spain are usually characterized by low sea-level pressures over inland North Africa and high pressures over central Europe. This setting produces easterly flow over the western Mediterranean, which together with the very warm and moist air over the Mediterranean Sea, favor the advection of conditionally unstable air towards the eastern coast of Spain. At mid-tropospheric levels, a cold deep trough to the west or southwest of the Iberian Peninsula and a ridge over central Europe bring the stationarity of the meteorological situation and enhance the low-level easterly circulation. This configuration promotes the impinging of unstable air over the coastal ranges, releasing its latent instability and initiating quasi-stationary heavy rain bearing moist deep convection systems.

More information about meteorological extremes in Spain can be found in http://www.aemet.es/es/serviciosclimaticos/ datosclimatologicos/efemerides_extremos.

Acknowledgements. The database of historical daily precipitation records is owned and maintained by AEMET. The used data have been obtained from collaboration with the EXTREMBLES (CGL2010-21869) project. S. Herrera from the ESTCENA team is acknowledged for his support. This work has been partially supported by the Spanish research project PREDIMED (CGL201124458).

Edited by: G. Panegrossi

Reviewed by: three anonymous referees

\section{References}

Adhikari P., Hong Y., Douglas K. R., Kirschbaum D. B., Gourley J. J., Adler R. F., and Brakenridge G. R.: A digitized global flood inventory (1998-2008): Compilation and preliminary results, J. Natural Hazards, 55, 405-422, 2010.

Anquetin, S., Yates, E., Ducrocq, V., Samouillan, S., Chancibault, K., Davolio, S., Accadia, C., Casaioli, M., Mariani, S., Ficca, G., Gozzini, B., Pasi, F., Pasqui, M., Garcia, A., Martorell, M., Romero, R., and Chessa, P.: The 8 and 9 September 2002 flash flood event in France: a model intercomparison, Nat. Hazards Earth Syst. Sci., 5, 741-754, doi:10.5194/nhess-5-741-2005, 2005.

EM-DAT: The OFDA/CRED International Disaster Database, available at: www.emdat.be, last access: 10 July 2013, Université Catholique de Louvain, Brussels, Belgium, 2013.

Font, I.: Climatología de España y Portugal, Instituto Nacional de Meteorología., 296 pp., 1983 (in Spanish) .

Hurrell, J. W.: Decadal trends in the North Atlantic Oscillation: regional temperatures and precipitation, Science, 269, 676-679, 1995.

Jenkinson, A. F.: The frequency distribution of the annual maximum (or minimum) of meteorological elements, Q. J. R. Meteorol. Soc., 81, 158-171, 1955.

Maddox, R. A.: Mesoscale Convective Complexes, Bull. Am. Meteorol. Soc., 61, 1374-1387, 1980.

Martin-Vide, J. and López-Bustin, J. A.: The Western Mediterranean Oscillation and rainfall in the Iberian peninsula, Int. J. Climatol., 26, 1455-1475, 2006.

Riosalido, R., Rivera, A., and Martin, F.: Development of a mesoscale convective system in the Spanish Mediterranean Area, Proc. 7th Meteosat Scientific Users' Meeting, Madrid 27-30 Sept. 1988, EUM P 04, 375-378, 1988.

Romero, R. and Ramis, C: Rainfall torrential patterns in Mediterranean Spain ans associated meteorological settings, Tethys, 2, available at: www.tethys.cat/antics/num02/articles/art0202eng. htm, last access: 2 September 2013, 2002.

Romero, R., Ramis, C., and Alonso, S.: Numerical simulation of an extreme rainfall event in Catalonia: Role of orography and evaporation from the sea, Q. J. R. Meteorol. Soc., 123, 537-559, 1997.

Romero, R., Guijarro, J. A., Ramis, C., and Alonso, S.: A 30 year (1964-1993) daily rainfall data base for the Spanish Mediterranean regions: First exploratory study, Int. J. Climatol., 18, 541$560,1998$.

Romero, R., Doswell, C. A., and Ramis, C.: Mesoscale numerical study of two cases of long-lived quasiestationary convective systems over Eastern Spain, Mon. Weather Rev., 128, 3731-3751, 2000.

Romero, R., Doswell, C. A., and Riosalido, R.: Observations and fine-grid simulations of a convective outbreak in northeastern Spain: importance of diurnal forcing and convective cool pools, Mon. Weather Rev., 129, 2157-2182, 2001.

Sánchez, J. L., Fernández, M. V., Fernández, J. T., Tudurí, E., and Ramis, C.: Analysis of mesoscale convective systems with hail precipitation, Atmos. Res., 67-68, 573-588, 2003.

Valencia, J. L., Tarquis, A. M., Saá-Requejo, A., and Gascó, J. M.: Change of extreme rainfall indexes at Ebro River Basin, Nat. Hazards Earth Syst. Sci., 12, 2127-2137, doi:10.5194/nhess-122127-2012, 2012.

Venables, W. N. and Ripley, B. D.: Modern applied statistics with S, Springer, New York, 435-446, 2002. 